\title{
Modeling of a cracked and repaired A1 2024T3 aircraft plate: effect of the composite patch shape on the repair performance
}

\author{
Baghdadi Mohammed, Serier Boualem, Salem Mokadem, Zaoui Bouchra, Kaddouri Khacem \\ University of Djillali Liabes, Laboratory of Mechanics Physics of Materials (LMPM Laboratory), Sidi Bel Abbes, Algeria. \\ mobbagb0@gmail.com,boualems@yahoo.fr,Moka_salem@yahoo.fr,raouibouchra55@yahoo.com,kaddourikacem@yahoo.fr
}

\begin{abstract}
In this work the finite element method was used to analyse the composite patch shape effect of the repair performance. Unlike all the works done conducted so far in this domain, this work proposed here, takes into account the reducing both, the stress intensity factor in repairing crack heads and the maximum shear stresses in the adhesive layer. This is the originality of this work. In function of the surface and the volume of the rectangular patch, three cases were taken into consideration: with conservation of the patches surface and its volume, with a reduction of the patches surface and its volumes, and in the end, with a reduction of the patches surface and conservation of its volume. The obtained results show that in the first case, the patch shape have no effect on the SIF, the sharp edges (obtuse, right and acute) of oblique shapes generate high shear stresses, in the second case, the reduced surfaces lead to significant mass gain with the same SIF values. and to an increase in the maximum shear stresses, in the latter case the patches shapes lead to a reduction of the SIF and the shear stresses.
\end{abstract}

KEYwORDS. Patch; Composite; SIF; Stress; Shape; Adhesive; Crack.

\section{open ACCEss}

Citation: Baghdadi, M., Serier, B., Salem, M., Zaoui, B., Kaddouri, K., Modeling of a cracked and repaired $\mathrm{Al} 2024 \mathrm{~T} 3$ aircraft plate: Effect of the composite patch shape on the repair performance, Frattura ed Integrità Strutturale, 50 (2019) 68-85.

Received: 18.02 .2019

Accepted: 07.07.2019

Published: 01.10.2019

Copyright: (C) 2019 This is an open access article under the terms of the CC-BY 4.0, which permits unrestricted use, distribution, and reproduction in any medium, provided the original author and source are credited.

\section{INTRODUCTION}

$\mathrm{T}$ he birth of cracks in a structure metal in any field, such as aeronautical and marine structures, is a major concern of maintenance operators. To extend the life of these structures, Becker [1] has developed a repair technique which consists of bonded a composite patch with polymer matrices, usually epoxy, on the cracked area. This technique has shown its effectiveness in reducing of the stress intensity factor (SIF) at the crack tip, and by improving the behaviour of the damage structures durability [2,3]. In addition to their high stiffness, these composites materials offer good corrosion resistance and low density. The quality of the repair depends on several parameters, geometrical and mechanical on the composite patch and the adhesive layer. Thus, the composite patches shapes seem to be a determining element of the repair effectiveness. This is the objective of several research projects, Bouchiba and al [4] have developed a static approach to optimise the composite patch shape, they conclude that the butterfly shape reduces the failure energy in 
the crack tip and minimise the shear stresses in the adhesive layer. Mhamdia and all [5], proceeding at conception of a new patch shape, named patch double arrow, show that, compared with the conventional rectangular shape, this shape, resulting in a more performing and more efficient repair in terms of the normal tension stresses relaxation, highly concentrated in the crack heads. Chung K.H and al [6, 7], Jeong Gi-Hyeon and all [8], by analysing the efficiency of patch geometry, from a point of view, fracture mechanics and disbonding of the patch, proceeded with the development of a composite patch geometry leading to the maximum reduction of the SIF. Ramji and Srilakshmi [9], by analysing the repair of the structure solicited in mixed mode with composite patch, have shown that the SIF in repairing crack is insensitive to the patch shapes. In another study, Ramji and al [10], studying the effect of the circular, square, rectangular, elliptical and octagonal shapes of the patch on the crack repair efficiency in mixed mode, they concluded that, the rectangular and octagonal shapes are the performances, in terms of the SIF reducing. Kashfuddoja and all. [11] developed this analysis by adding the elliptical shape, they studied the effects of these shapes on the repair quality in terms of reducing of the stress concentration factor "SCF" in the circular notch vicinity located in a plate centre, repaired with a composite patch unidirectional, by comparing the values of these parameter resulting from these different shapes, these authors have shown that the octagonal patch elongated perpendicular to the traction direction, is the most effective shape. Fekih and al [12], analysed the patch shapes effect on the durability and reliability of the repair, in term of "J" integral reducing, shown that the patch shaped star is the most effective. Mahadesh Kumar and all. [13] analysed the values of the SIF resulting from the repair using four principal regular patches geometries, square, rectangular, circular and elliptical. They show as well, from a point of view a reduction of this parameter, that the classic rectangular shape with important elongation in the direction parallel to the crack, is the most effective. Based on these findings, these authors have developed a new patch shape, called "skewed patch", They concluded that, this last, leads to a mass gain around $28 \%$ in practically the same value of the SIF. Or it reduces this value of $10 \%$ for the same volume of the patch. Mohamed Ibrahim and all [14], analysed the effect of a rectangular patch on the repair performance of the two cracks interaction. This analysis is done in terms of reducing the stress intensity factor in mode I.

This work fits into this context and aims to analyse the effect of the patch composite shapes on the efficiency and performance of the repair, in terms of reduction of the stress intensity factor in cracks heads and the shear stresses in all the adhesive layer. A finite element method was used for this analysis. For this purpose, a geometric model has been developed.

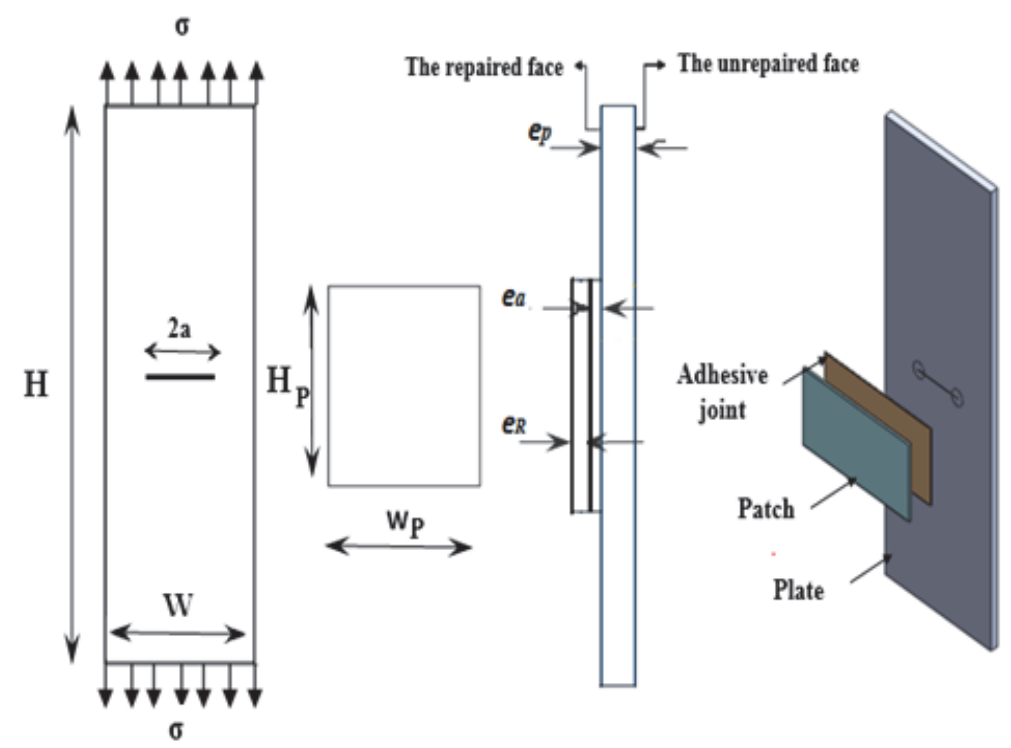

Figure 1: Geometric model of the structure.

\section{GEOMETRIC MODEL}

$\mathrm{T}$

he geometric model developed consists of a 2024-T3 aluminium alloy plate of an aircraft structure, this plate is characterized by its height $\mathrm{H}=250 \mathrm{~mm}$, its width $\mathrm{W}=125 \mathrm{~mm}$ and its thickness ep $=2 \mathrm{~mm}$. This plate is subjected to uniaxial tension stresses of varying amplitude, allowing the crack propagation in opening mode, the 
most dangerous mode. The composite patch, defined by its height $\mathrm{Hp}$, its width $\mathrm{Wp}$, and its thickness $\mathrm{e}_{\mathrm{R}}=2 \mathrm{~mm}$, is supposed to be perfectly bonded to the plate by an FM-73 adhesive type of thickness $e_{a}=0.2 \mathrm{~mm}$ (fig.1). The mechanical properties of the plate, the patch and the adhesive are shown in Tab. 1.

\begin{tabular}{cccc}
\hline Properties & $\begin{array}{c}\text { Plate AL } \\
(2024-\mathrm{T})\end{array}$ & $\begin{array}{c}\text { Carbon /epoxy } \\
\text { Engineering Constants }\end{array}$ & $\begin{array}{c}\text { FM-73 } \\
\text { Adhesive type }\end{array}$ \\
$\mathrm{E}_{1}(\mathrm{MPa})$ & $7210^{3}$ & $15310^{3}$ & $2.5510^{3}$ \\
$\mathrm{E}_{2}(\mathrm{MPa})$ & ---- & $9.110^{3}$ & ---- \\
$\mathrm{E}_{3}(\mathrm{MPa})$ & ---- & $9.110^{3}$ & ---- \\
$\nu_{12}$ & 0.33 & 0.258 & 0.3 \\
$\nu_{13}$ & ---- & 0.258 & ---- \\
$\nu_{23}$ & ---- & 0.384 & ---- \\
$\mathrm{G}_{12}(\mathrm{MPa})$ & ---- & $4.5710^{3}$ & 420 \\
$\mathrm{G}_{13}(\mathrm{MPa})$ & ---- & $4.5710^{3}$ & ---- \\
$\mathrm{G}_{23}(\mathrm{MPa}$ & ---- & $3.1510^{3}$ & ---- \\
\hline
\end{tabular}

Table 1: Mechanical properties of the materials.

\section{Presentation OF THE Calculation SOFTWARE USED IN THIS STUdY}

7 he performance of Abaqus software version 6.11 [15] is used for the analysis of cracked aircraft plates and after repaired with composite patches. Abaqus software has many finite element analysis capabilities, ranging from a simple linear static study to another complex nonlinear static. The documentation of this software gives the procedures to be followed to make analyses of different fields of engineering. The ultimate objective of finite element analysis is to recreate mathematically the behaviour of a true engineering system. In other words, the analysis must be based on a precise mathematical model of a physical prototype.

\section{Presentation of the Model}

$\mathrm{T}$ he three-dimensional numerical model developed for this study consists of a cracked Al2024 T3 plate repaired by composite patch (carbon-epoxy) (fig. 1). Finite element modelling requires the mesh of the structure to be analysed. The choice of the types and sizes of elements to be used, especially in the crack tip depends on the fundamental parameters, to control the strong gradients of stresses and deformations in the vicinity of the crack tip vicinity, the first step is to choose the type of element, the most adapted to the problem studied, then we divide the structure into a number of elements. In general, and according to the fracture mechanics and the finite element modelling of a cracked plate, the structure has been meshed globally using elements of the type C3D8. (An 8-node linear brick) (fig.2). To obtain a correct representation of the displacement field near the crack, the elements called singular are used, as suggested by the Abaqus software documentation. The type of singularity $1 / \sqrt{ }_{\mathrm{r}}$, for the stress fields are obtained by moving all the intermediate nodes of the elements around the crack tip to a quarter of a distance from the nodes belonging to the considered crack tip. The mesh of the crack tip was exclusively refined using this special type element (fig.2). The total number of elements for the repaired structure depends on the patch shape. For the rectangular patch, the total number of elements is shown in Tab. 2.

\begin{tabular}{lcc}
\hline $\begin{array}{l}\text { The different components } \\
\text { of the analysed structure }\end{array}$ & Numbers of elements & Sizes of elements \\
Aluminium 2024-T3 & 11796 & $2 \mathrm{~mm}$ \\
Cracking front & 2500 & $0.078 \mathrm{~mm}$ \\
FM-73 Adhesive type & 3200 & $0.5 \mathrm{~mm}$ \\
Composite Patch & 12800 & $0.5 \mathrm{~mm}$ \\
\hline
\end{tabular}

Table 2. Numbers and sizes of the mesh elements. 
The side sizes of an element, far from the crack and in the crack vicinity, was represented in Tab. 2. This sizes and types of mesh, remains the same for all the simulations in this work, to avoid any influence of the mesh on the results.
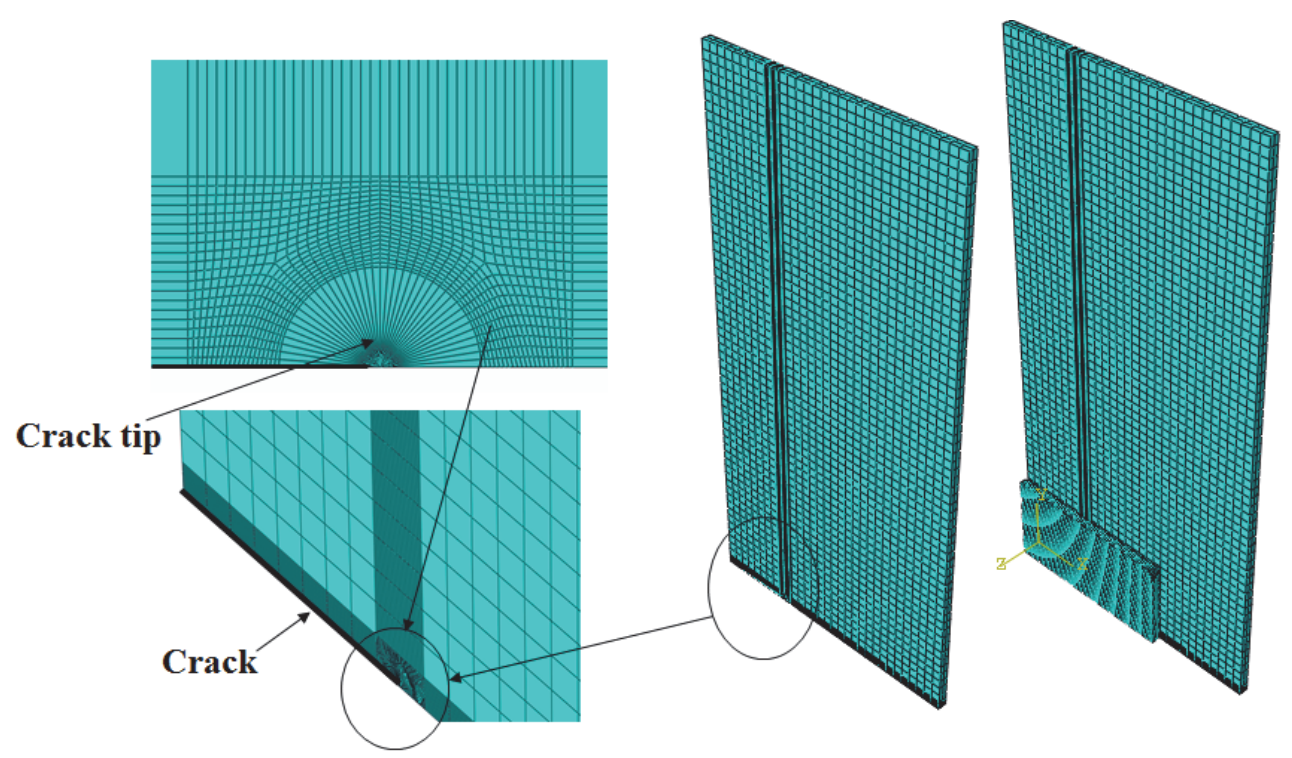

Figure 2: Mesh of the structure.

Adhesive has been considered as a third material to introduce its actual mechanical properties. The interaction between adhesive and the cracked plate area, firstly, and between the composite patch and adhesive, secondly is considered perfectly welded (the two bodies can be considered welded during the simulations).

The symmetry allows the modelling of the structure quarter, which leads to a reduction in calculation times, the boundary conditions imposed on the plate analysed are represented as follows (Fig. 3):

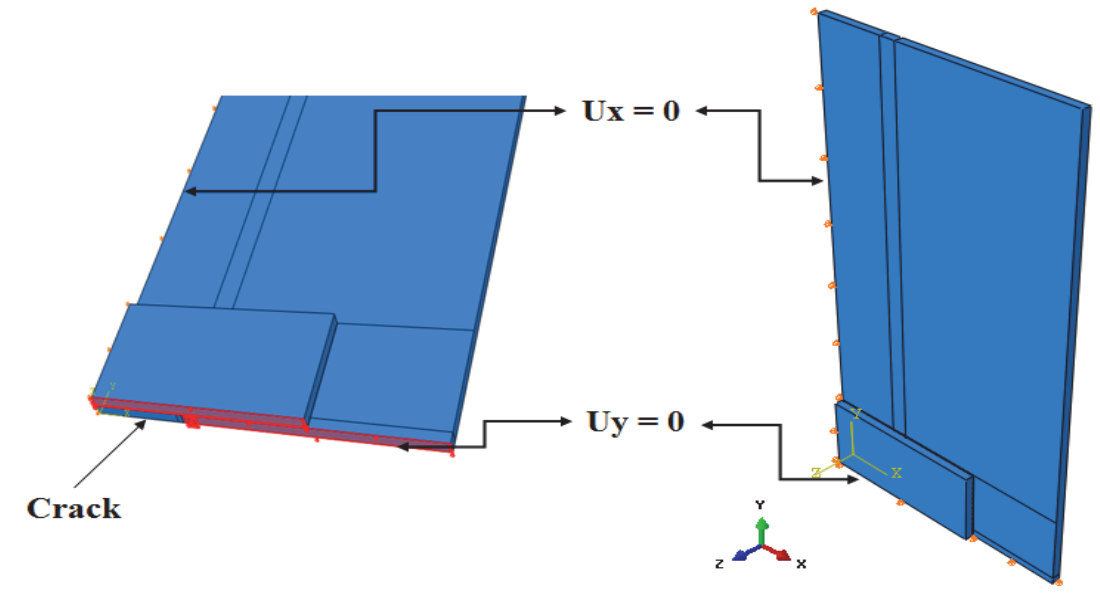

Figure 3: Boundary conditions imposed on the structure.

\section{VALIDATION OF THE MODEL}

1 o validate the model developed in this work, Fig. 4 shows a comparative analysis of the SIF variation obtained from the numerical model, developed in this work, and that resulting from an analytical model. The SIF is the only significant parameter, which allows to know the state of stress and deformation in any crack heads. For a central crack solicited in opening mode, the relation between the far applied stress on the plat $(\sigma)$ and the stress intensity factor $\mathrm{K}_{\mathrm{I}}$ is as follows:

$$
\mathrm{K}_{\mathrm{I}}=\mathrm{Y} \sigma \sqrt{\pi a}
$$


where $\mathrm{Y}$ is a geometric factor, depends on the plate geometry and the crack shape. $\mathrm{Y}=1.12$ (for a finished plate containing a central crack "2a"). The analysis of this result shows that the numerical and the analytic model lead practically the same results and whatever the applied stress intensities to the plate. This behaviour clearly illustrates that the model developed in this study and the boundary conditions imposed are reliable and allows a better mechanical behaviour analysis of the cracked structure and repaired with composite patch.

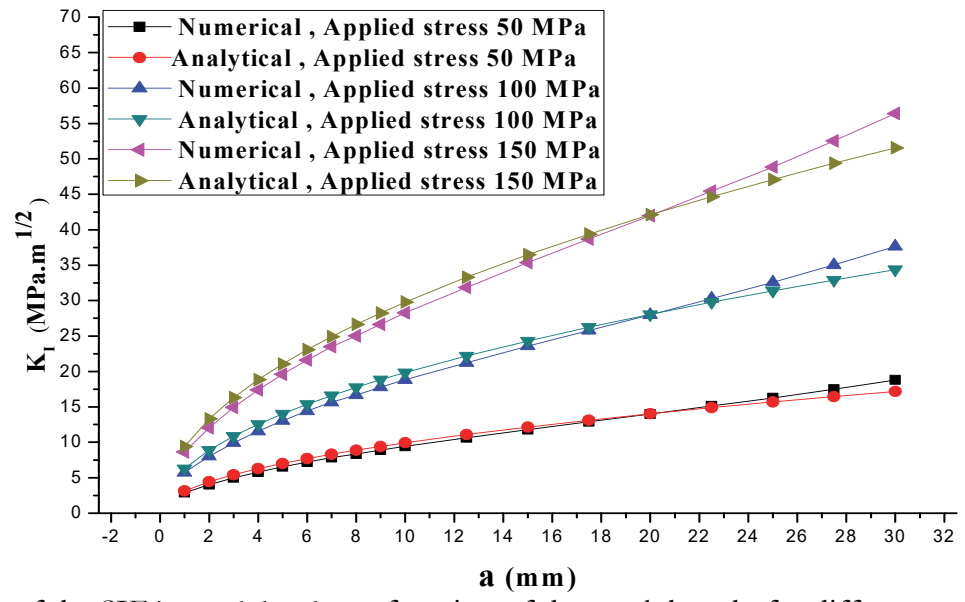

Figure 4: Variation of the SIF in crack head as a function of the crack length, for different applied stress intensities

These conditions will be retained along in this work and will allow a reliable analysis of the patch shape effect on the performance of the repair.

\section{RESULTS AND DISCUSSION}

I t has been reported previously that the composite patch shapes have a significant effect on the performance and reliability of the repair in terms of reduction of the stress intensity factor in crack heads and the shear stresses in the adhesive layer. The reduction of these two physical parameters is required for the stability and durability of cracked structures repaired with composite patches.

\section{EFFECT OF THE PATCH GEOMETRIC PARAMETERS (HEIGHT HP AND ITS WIDTH WP)}

7 he cracked plate is repaired using a rectangular carbon-epoxy patch, characterized by its height Hp and its width Wp (Fig.1). The junction between these two structures is ensured by means of an FM73 adhesive type. The latter has been very often used in many works in the patch repair case.

The objective of this study is to analyse the effect of these two geometrical parameters $\mathrm{H}_{\mathrm{P}}$ and $\mathrm{W}_{\mathrm{P}}$ on the repair quality in terms of SIF reduction in opening mode. The results obtained are illustrated in Fig. 5. The analysis of the (Fig. 5, a), clearly shows that the SIF decrease when the repair is done by a wider patch. Whatever the applied stress intensities, the repair becomes more and more effective and efficient with the use of the wider patch. This behaviour was observed by Dajmel Ouinas [16] and al, Mahadesh Kumar and al. [13] and confirmed by Ramji and al. [10] as well as by Kashfuddoja and al. [11] that have demonstrated the effectiveness of designing an elongated patch in the direction perpendicular to the tensile loading. This efficiency is closely related to optimizing the height of this patch, noted $\mathrm{H}_{\mathrm{P}}$, it is clearly shown that the composite patches with higher heights lead to a clear decrease in the SIF in mode I (Fig 5.b). For the more important height of the patch, this geometrical parameter does not appear to play an important role in improving the service life of the repair in terms of SIF reduction (Fig5. b). In fact, there is a threshold value beyond which this rapture parameter does not vary with increasing the height of the patch. As shown in (Fig. 5, b).

The results obtained in Fig. 5, show more clearly the possibility of determining an optimal height of a rectangular patch, Nevertheless, this last is closely related to its width. In our simulation conditions, for a repaired crack size of "a $=18 \mathrm{~mm} "$ and whatever the applied stress intensities, for width values greater than or equal to "W $>72 \mathrm{~mm}$ ", the optimum height $H_{P}$ is equal to $40 \mathrm{~mm}$. In this case, the repair is only effective if $W_{P}>H_{P}$, in other words, the repair is effective only if the 
rectangular patch has a height (perpendicular to the crack) is less than its width (parallel to the crack). These results are in good agreement with those obtained by Mahadesh Kumar and al. [13].
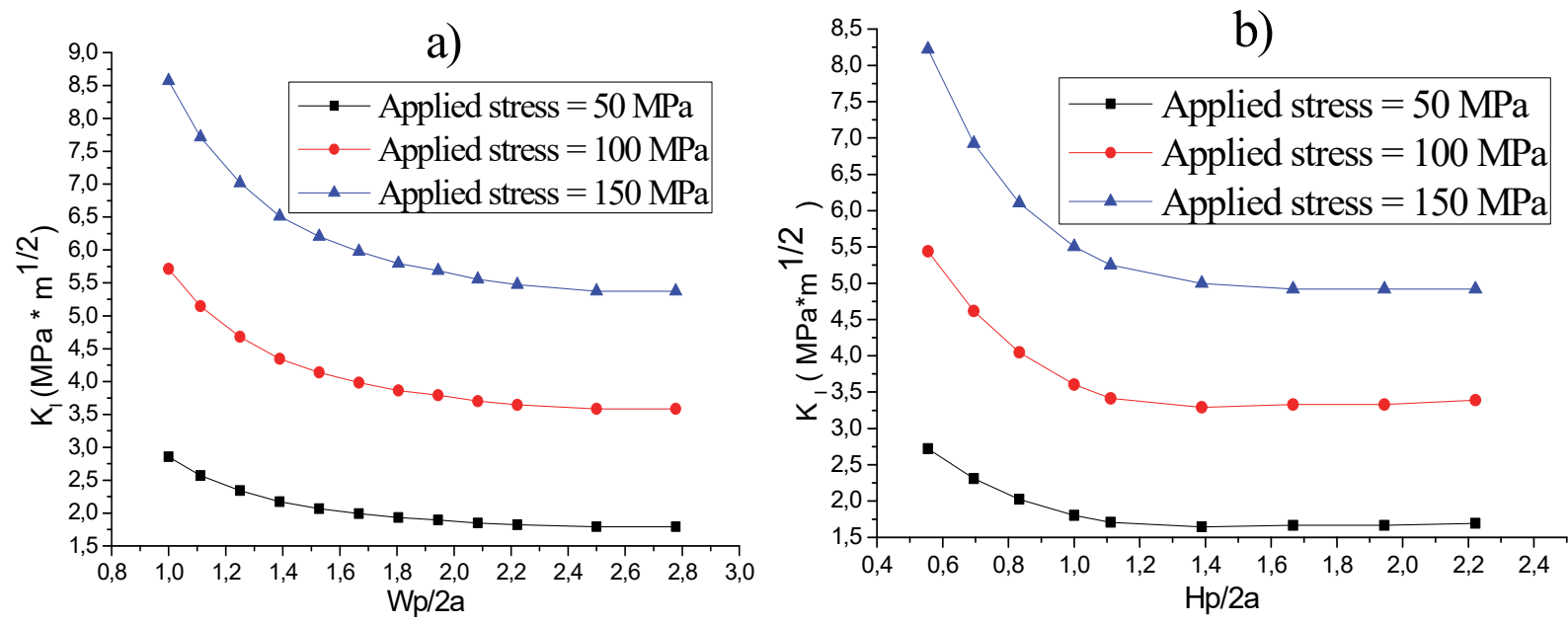

Figure 5: Variation of the SIF for different applied stress intensities, repaired crack a $=18 \mathrm{~mm}$. a) as a function the composite patch width, b) as a function of the composite patch height. $(=18 \mathrm{~mm})$

These results explicitly show the interaction between the width $\left(\mathrm{W}_{\mathrm{P}}\right)$ and the height $\left(\mathrm{H}_{\mathrm{P}}\right)$ of a rectangular patch in the determination of the SIF in crack heads and the shear stresses in the adhesive layer. which leads us to think that the optimization of the patch should go through by other shapes for which the height varies with the width. The interaction between these two geometric parameters (width and height) of the patch, shows the need to perform an optimization analysis to predict the best variation of these dimensions, allowing the reduction of the SIF in crack heads as well as shear stresses in the adhesive layer.

\section{EFFECT OF THE PATCH SHAPE ON THE STRESS INTENSITY FACTOR ON THE CRACK HEADS}

7 he sizes of the patch shapes were deduced from the height $\mathrm{Hp}$ and the width Wp of the initial rectangular patch which were optimized according to the size of the repaired crack $(\mathrm{a}=18 \mathrm{~mm})$, according to the results shown in (Figs. 5).

Seven shapes of patches were selected for this analysis: rectangular, arrows-shaped, H-shaped, Trapezoidal, elliptical, octagonal and butterfly-shaped.

The effect of these shapes on the repair performance, in terms of reduction of the SIF in crack heads and shear stresses in the adhesive layer, is made in three steps: with conservation of the patch surface and its thickness (Fig.6), with a variation of the patch surface and conservation of its thickness (Fig.8), and in the end, with a variation of the patch surface and its thickness (Fig.10).

\section{Patch with conservation of the surface and its thickness}

Firstly, the repair is done with patches having the same surface and the same thickness (Fig 6). the compensation of the surface is done by playing on its $\mathrm{H}_{\mathrm{P}}$ height. These conditions allow the elimination of the other parameters effect, and lead to a more realistic analysis of the composite patch shape effect on the mechanical behaviour of cracked plate, in order to reduce the fluctuations of the results that may be due to the nature of the mesh elements. The same elements, the same sizes and the same simulation conditions have been retained. (Tab. 2).

The results obtained are shown in Fig. 7, which show that the SIF in crack heads repaired seems to be practically insensitive to the patch shape. This insensitivity, much more marked for short sizes cracks (less than $18 \mathrm{~mm}$ ), can be explained by the fact, that the overlapping surface is identical for all patch shapes analysed. This surface is a geometric parameter determining of the repair performance in terms of crack stability. The rupture criteria resulting from these patch shapes, converge to the same value.

The repair of larger sizes cracks resulting in a negligible fluctuation of the SIF. This leads to say that, contrary to the results obtained by $[17,18]$, when the overlapping surface of the cracked zone remains invariable, the patch shape has no 
effect on the repair efficiency in terms of fracture energy reduction in mode I. In fact, the sharp edges (obtuse, right and acute) of these patch shapes, are positioned too far from the crack heads, which considerably reduces their effect of indefinitely storing normal stresses, strongly localised in this crack heads. These results explicitly show that it is the overlapping surface of the damaged part that controls the mechanical behaviour of the repair using patches of different shape. So, it will be wise to analyse the response of these repaired structures using these same patch shapes with variable overlap surface.

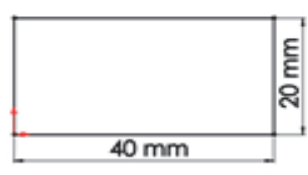

Rectangular patch $\mathrm{s}=800 \mathrm{~mm}^{2}$

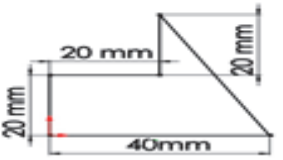

Patch shaped arrow $\mathrm{s}=800 \mathrm{~mm}^{2}$

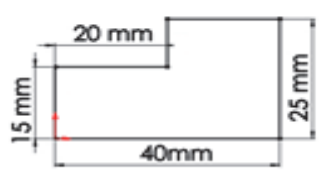

Patch shaped $\mathbf{H}$

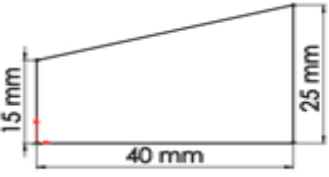

Trapezoidal patch $\mathrm{s}=800 \mathrm{~mm}^{2}$

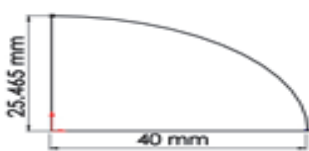

Elliptical patch $\mathrm{s}=800 \mathrm{~mm}^{2}$

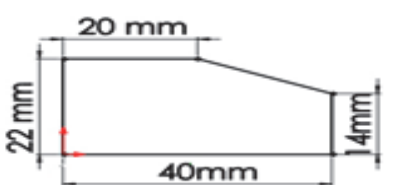

Octagonal patch $\mathrm{s}=800 \mathrm{~mm}^{2}$

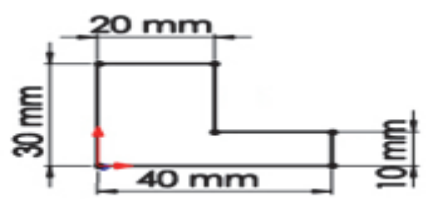

Patch shaped Butterfly

$\mathrm{s}=800 \mathrm{~mm}^{2}$

Figure 6: The different dimensions of the quarter of the patch shapes (constant surfaces ant thicknesses).
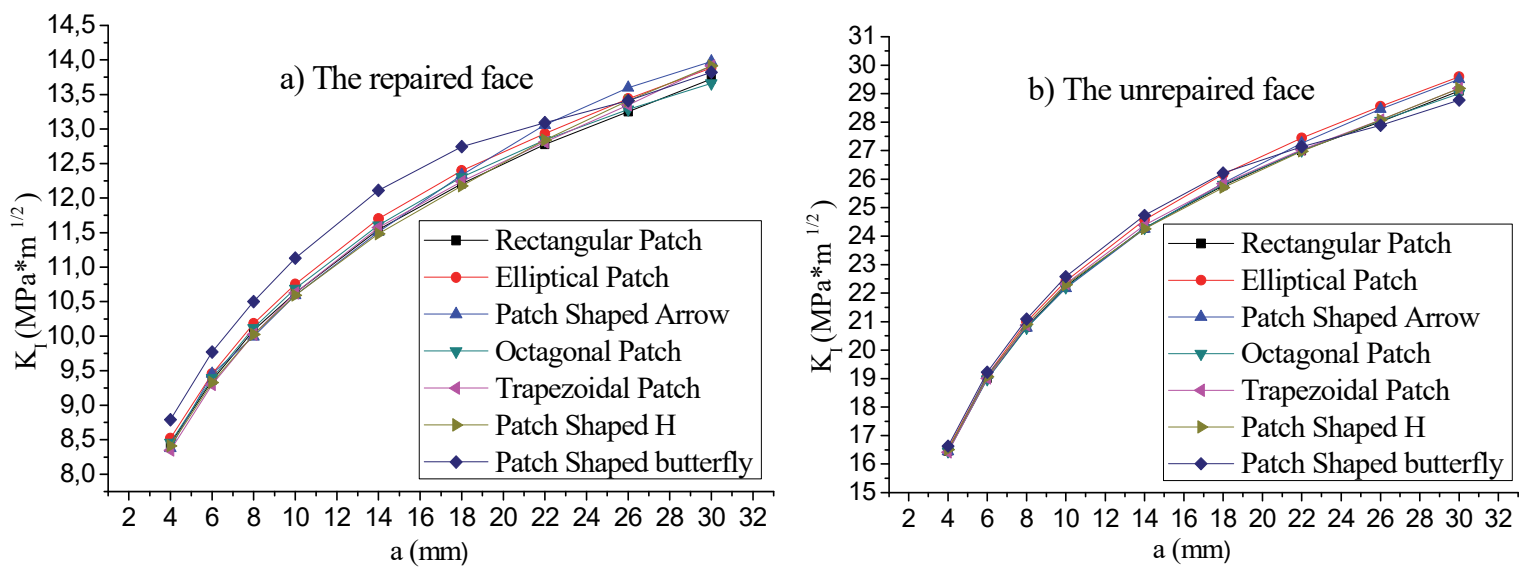

Figure 7: of the patch shape on the SIF level, Applied stress $150 \mathrm{MPa}$. a) repaired face, b) unrepaired face.

\section{Patch with a variation of the surface and conservation of its thickness}

To develop this study, all the patches shapes, analysed previously are deduced from a rectangular patch (Fig.8). The seven patches obtained have variable surface. The Fig. 9, illustrates the shape effect of such patches on the variation of the SIF in mode I, this results clearly shows that this rupture criterion does not vary much with the variation of this patch shape (Fig.9a). The same behaviour is observed on the unrepaired face of the plate (Fig.9b). For repairing cracks smaller than "a $<18 \mathrm{~mm}$ ", the patch shape has virtually no effect on the repair quality in terms of rupture parameter reducing (Fig. 9). Beyond this size, a slight variation of this parameter is observed. He noted, however, that such cracks $(\mathrm{a}>18 \mathrm{~mm})$ remain virtually theoretical for the repair performance prediction. The global analysis of the cracked structure shows that this performance is almost insensitive to the patch shape.

Remember that compared to the rectangular patch, all other shapes have a much smaller overlapping surface (Fig 8). It is relevant to note that the patch shaped arrow has a surface that is doubly smaller than the surface of the rectangular patch. Which is very interesting, from a point of view, mass gain, corresponding to a value of $50 \%$. Compared to the rectangular patch, all the other shapes lead to a significant mass gain and practically at the same values of the SIF. This clearly shows that the composite patch shape control significantly the repaired cracks behaviour. 
A surface twice as small, leads to the same values of the fracture energy in crack heads (Fig 9, a). The values of the SIF recorded on the unrepaired face of the plate are higher when the repair is done by using patches with an important overlapping surface (Fig.9b). This shows that the risk of the plate bending is minimized when the repairs is done by patches with greatly reduced on the overlapping surface. Such behaviour is only possible by modifying the composite patch geometry. This change results in sharp edges (obtuse, straight, acute) located very close of crack heads, thus promoting a large normal stress located in this crack head, transfer to the patch. To better understand this effect, an analysis of this modification with conservation of its volume is necessary. In other words, with modification of the patch surface and its thickness (Fig.10).

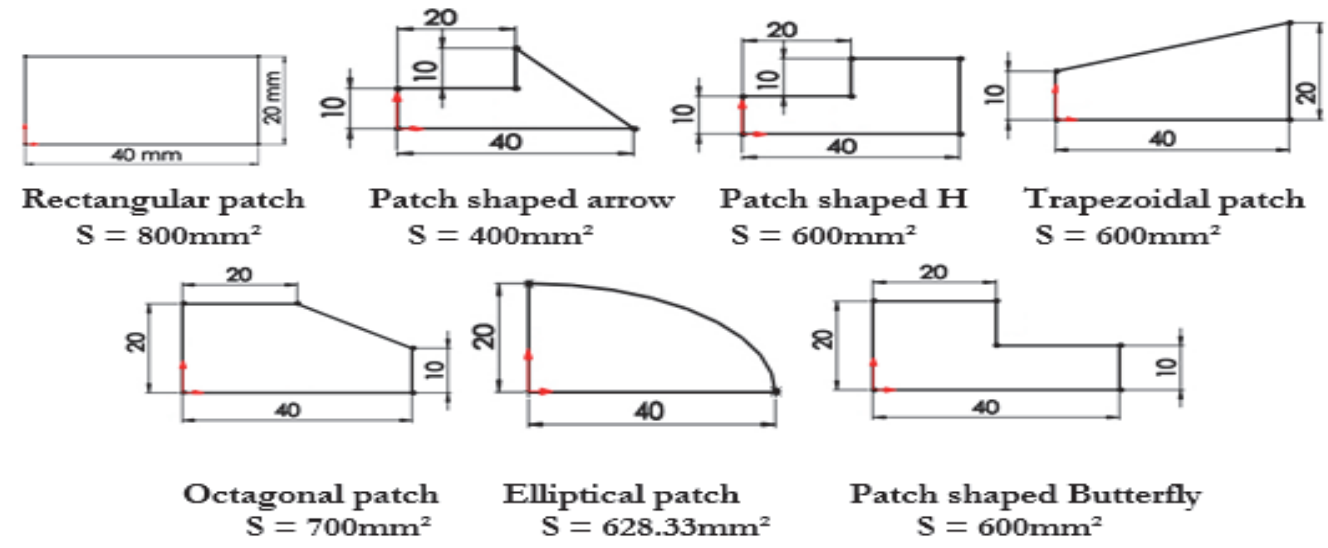

Figure 8: The different dimensions of the quarter of the patch shapes (variation surfaces and constant of its thicknesses).
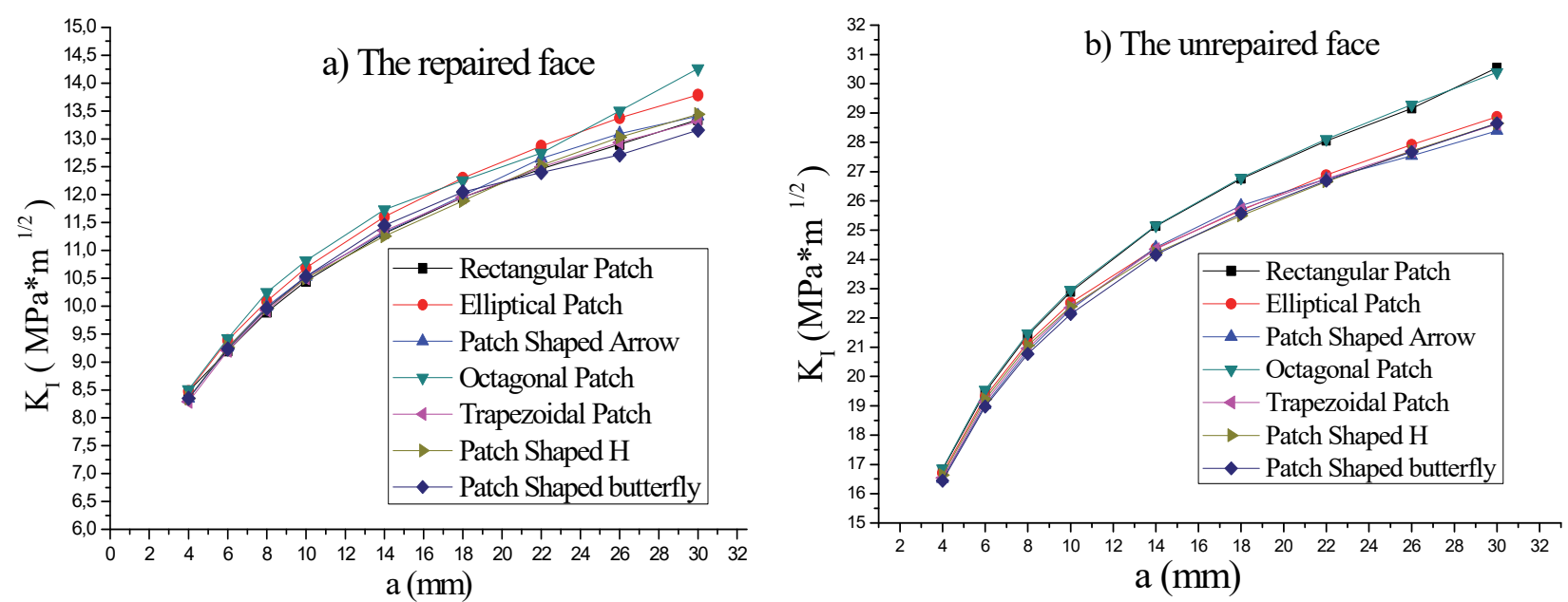

Figure 9: Effect of the patch shape on the SIF level, Applied stress $150 \mathrm{MPa}$. a) repaired face, b) unrepaired face.

Several works $[4,5,13,19-22]$ have focused on the analysis of the patch shapes effect on the quality of the repair in terms of stress intensity factor reduction. These shapes have been optimised to reduce two parameters, the mechanical energy, highly concentrated in crack head (energy gain) and the composite patch mass (mass gain). Taking into account this last parameter, our results are in good agreement with this works. In contrast to these, our study exclusively considers the impact of patch shapes on repair performance from a point of view, level and distribution of the shear stresses in the adhesive layer.

\section{Patch with variation of the surface and its thickness}

To complete this study, the same volume was used for all these shapes with variation of the surface. The variation of the patches thickness makes it possible to obtain constant volume (Fig.10). The Fig. 11, represents the SIF variation of the repaired face and unrepaired face by such patches respectively. The analysis of this result clearly shows that the repair using patches with smaller overlapping surface lead to the lower values of this rupture parameter. In other words, the 
repair is more efficient when done by thick patches and less extensive (small surfaces). This thickness is a fundamental parameter where the composite patch stiffness is stronger. So, in terms of fracture energy reducing in repairing cracks heads, the patch shaped arrow is more efficient. At equal volume and in the case of the long crack repair, it has, compared to the rectangular patch, an energy gain about $45 \%$ on the unrepaired face (Fig. 11.b) and about $25 \%$ on the repaired face (Fig. 11.a). This patch shape greatly reduces the instability of the crack on the unrepaired face and minimize the risk of plate bending.

In conclusion, from a point of view, fracture energy reduction in crack heads of repaired face and unrepaired face, and in terms of minimizing the bending due to the stiffness of the repair material, the patch shaped arrow is the most effective. Compared to all the other patch shapes, this shape leads to a significant mass gain, which is an economic issue, not negligible in aircraft structural repairs.

At constant volume of the composite patch, and in terms of fracture energy relaxation of the repaired and unrepaired face, and reduction of the plate bending effect, this shape remains the most efficient.

It would be wise to analyse the effect of these shapes and particularly of this shape on the level and distribution of the shear stresses in the adhesive layer. It is clear that the minimization of this parameter plays a determining role on the repair performance in terms of improving the aircraft service life. These stresses are usually responsible for the disbonding of the repair.
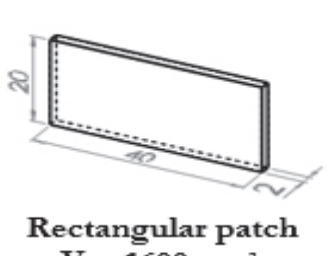
$\mathrm{V}=1600 \mathrm{~mm}^{3}$

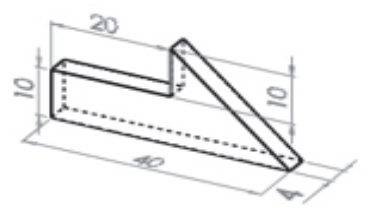

Patch shaped arrow $\mathrm{V}=1600 \mathrm{~mm}^{3}$

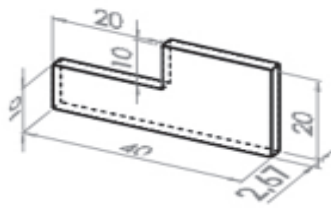

Patch shaped $\mathbf{H}$ $\mathrm{V}=1600 \mathrm{~mm}^{3}$

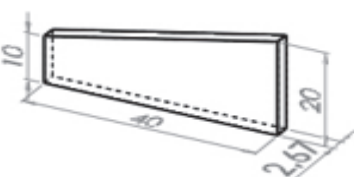

Trapezoidal patch $\mathrm{V}=1600 \mathrm{~mm}^{3}$

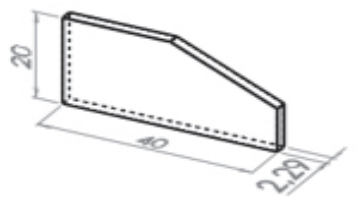

Octagonal patch $\mathrm{V}=1600 \mathrm{~mm}^{3}$

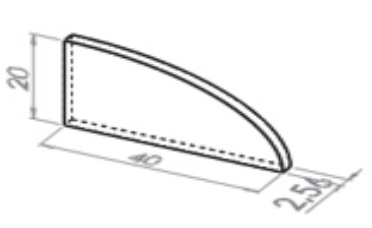

Elliptical patch $\mathrm{V}=1600 \mathrm{~mm}^{3}$

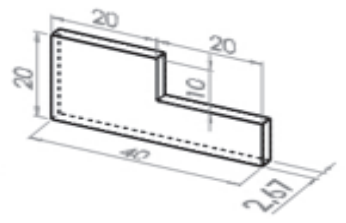

Patch shaped Butterfly $\mathrm{V}=1600 \mathrm{~mm}^{3}$

Figure 10: The different dimensions of the quarter of the patch shapes (constant volume).
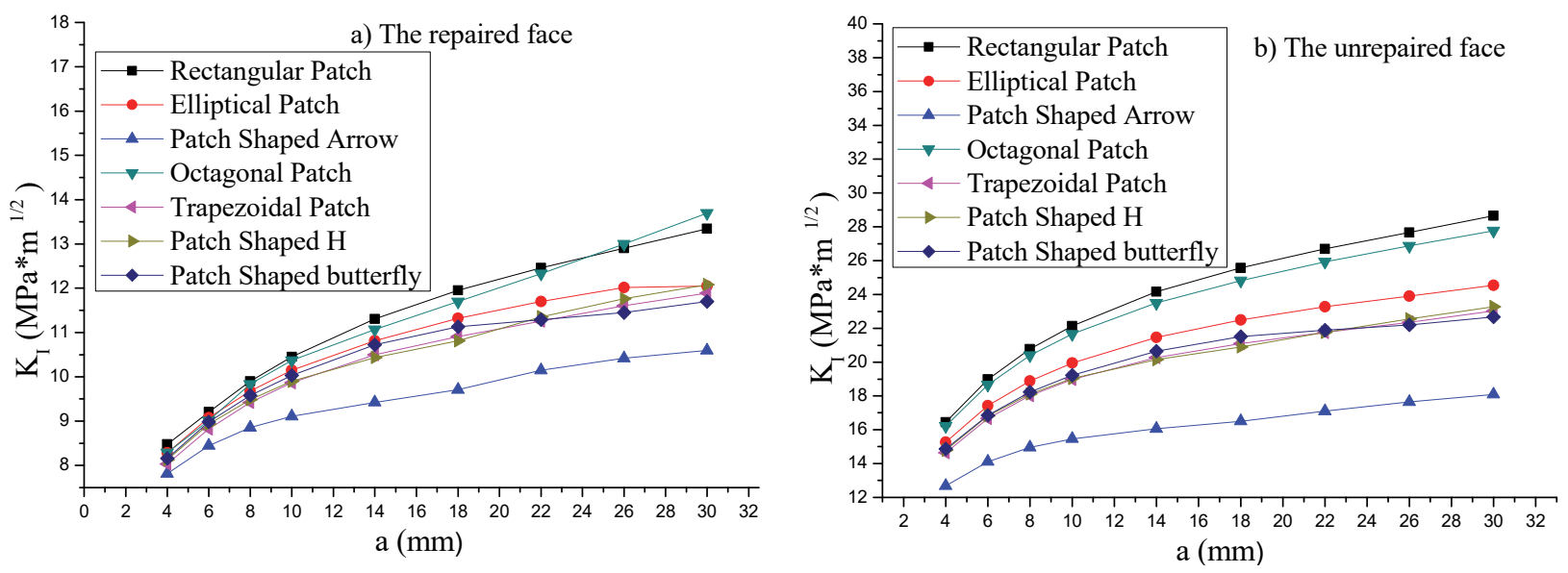

Figure 11: Effect of the patch shape on the SIF level, Applied stress $150 \mathrm{MPa}$. a) repaired face, b) unrepaired face. 


\section{EFFECT OF THE PATCH SHAPES ON THE SHEAR STRESSES LEVEL IN THE ADHESIVE LAYER}

I $\mathrm{t}$ is important to maintain the shear stresses in the adhesive layer at the lowest possible level. Any design of the patch shape aims not only to relax as much possible the fracture energy in crack heads, but also to reduce the intensity of these stresses in order to prevent the adhesion failure.

The performance of the composite patch repair depends essentially on the mechanical behaviour of the adhesive layer. This constitutes the weakest link of structure and practically the essential cause of the repair damage by the disbonding process. The comprehension of the mechanisms type degradation of the repair, is still only very superficial. The disbonding is a rather complex phenomenon whose physical mechanisms are still very poorly known, depends practically on the mechanical and geometrical parameters of the patch, and especially an induced the shear stresses in the adhesive layer, during the repair process. These stresses are generally responsible for the repair disbonding. Thus, several works have been devoted to such a type of degradation, among them can be cited the use of the zone damaged theory to explain the disbonding mechanisms due to the adhesive ruin. This theory is based primarily on the formation and development of a damaged zone, then on the crack propagation initiated in this zone, having reached a critical size, under more intense loads [23]. Crombr [24] and al, Sheppard [25] and al, have developed a model for predicting damage of the adhesive layer. They show that the degradation of this layer occurs when the stress induced in the adhesive crosses a threshold stress. These authors conclude that this degradation is not the result of the repaired crack propagation, but rather the initiation and growth of new cracks in the adhesive layer. Ban and al. [26] have made the correction taking into account, the damaged zone ratio, defined by the ratio of the estimated surfaces sum, where the deformation at fracture is reached, and the total adhesive layer surface. This model was used as a criterion for predicting damage to the adhesive. They conclude that the disbonding of an adhesive "type FM 73", occurs when this report tends towards an estimated limit value of 0.247. Based on this model, Ibrahim and al [27] analysed the degradation of the adhesive layer used for composite patch repair of cracked aircraft structures. Again, based on the same model, Papanikos and al [28] observed that the top edge of the patch is a source of disbonding initiation. They conclude that this disbonding, responsible for the partial decohesion of the assembled surfaces, leads to a considerable reduction in the effective surface of the junction. Magalhaes and al. [29], by analysing the nature of the adhesive layer degradation, have shown that the ruin is manifested inside the adhesive near the adhesive-adherent interface. The existence of an adhesive film on the bonded surface illustrates that the disbonding is the result of a cohesive failure of the adhesive.

The shear stresses induced in the adhesive layer are generally responsible for disbonding of structures repaired with composite patches. To complete the previous study, the effect of the patch shapes on the level and distribution of these stresses, is analysed. It is important to keep these stresses as low as possible.

The shear stresses were determined in the XOY, XOZ and YOZ planes along the propagation path (Fig. 12, 14 and 16), and the maximum shear stresses in the adhesive layer (Fig. 13,15 and 17), this is the originality of this work, virtually no studies have focused on analysing of the repair performance in terms of reducing of all shear stresses in the adhesive layer. Most numerical analytical works have analysed the effectiveness of repair from a point of view, a reduction of fracture energy $[4,5,13,19-22]$.

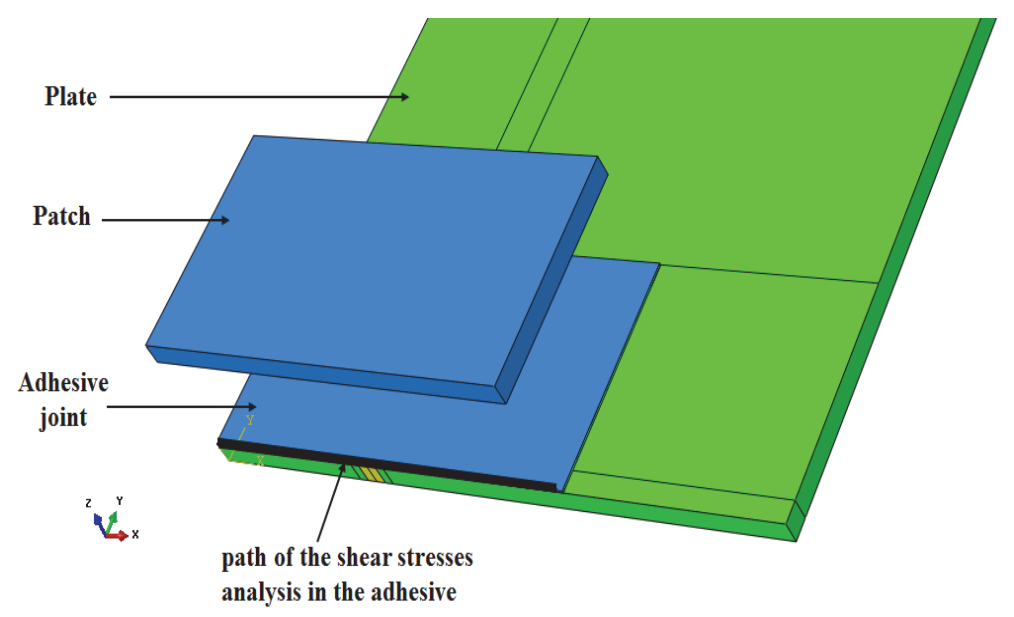

Figure 12: Path of shear stresses Analysis in the adhesive layer. 
Patch with conservation of the surface and its thickness

In this analysis, the repair was done by different patch shapes having the same surface (Fig. 6) and differing only in their geometry. Their effect on the level and distribution of the shear stresses in the adhesive layer are shown in Fig. 13 and 14. These results shows that in terms of relaxation of these stresses, the repair using an elliptical patch is the most effective and, whatever the plane of the structure (Fig 13a, b and c).
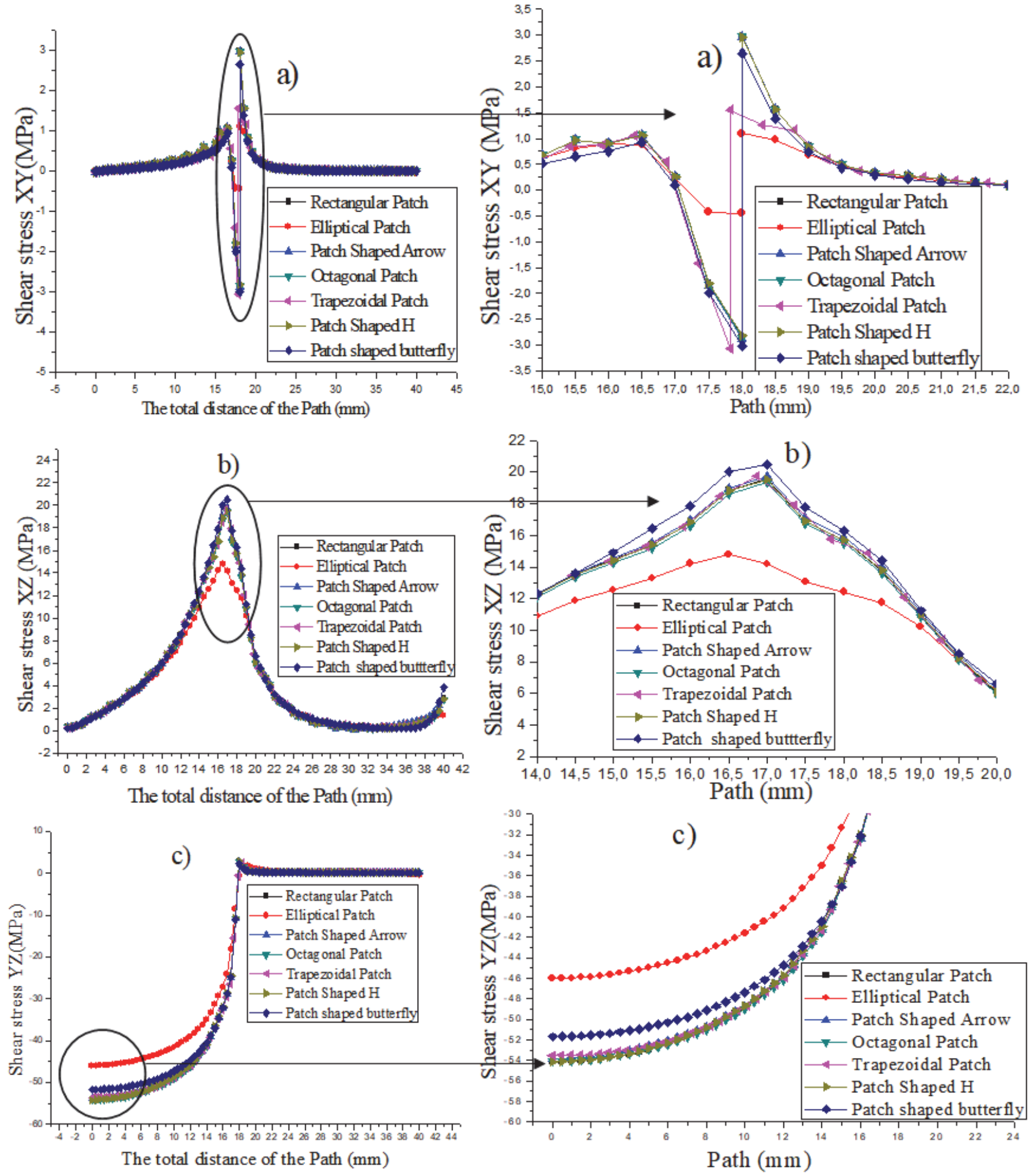

Figure 13: The effect of the patch shape on the shear stresses level in the adhesive layer along the crack propagation path. Repaired crack a $=18 \mathrm{~mm}$, Applied stress $=150 \mathrm{MPa}$. 
The maximum shear stresses in the adhesive layer are reduced by using an elliptical patch shape (Fig.14a, b and c). This results explicitly illustrates that the sharp or oblique edge effect, of other patches (rectangular, arrows-shaped, H-shaped, Trapezoidal, octagonal and butterfly-shaped), located sufficiently far from the crack heads, to store a high proportion of mechanical energy in this crack heads, is almost non-existent. These edges are sources of localised shear stresses at the free edges of the adhesive. For that, the level of the shear stresses in a repair using such patch shapes are high level. The highest tangential stresses due to the crack opening, are relative to the plane YOZ of the structure (Fig 13c). These stresses can lead to the degradation of the adhesion by a disbonding mechanism, this risk is minimized when the repair is done by an elliptical patch.

The results shown in Fig. 14c, illustrate the maximum shear stresses induced in the adhesive layer located on the free edge of the repair. These stresses increase with the sizes of the repaired crack, can lead to the initiation and propagation of cracks at the adhesive layer-plate interface, thus also leading to the disbonding of this repair. These results are in good agreement with those obtained by [30,31]. So, it is interesting to analyse the effect of the surface reduction of these patch shapes, with conservation of its stiffness. in other words, with constant of its thickness, on the mechanical behaviour of the repair.
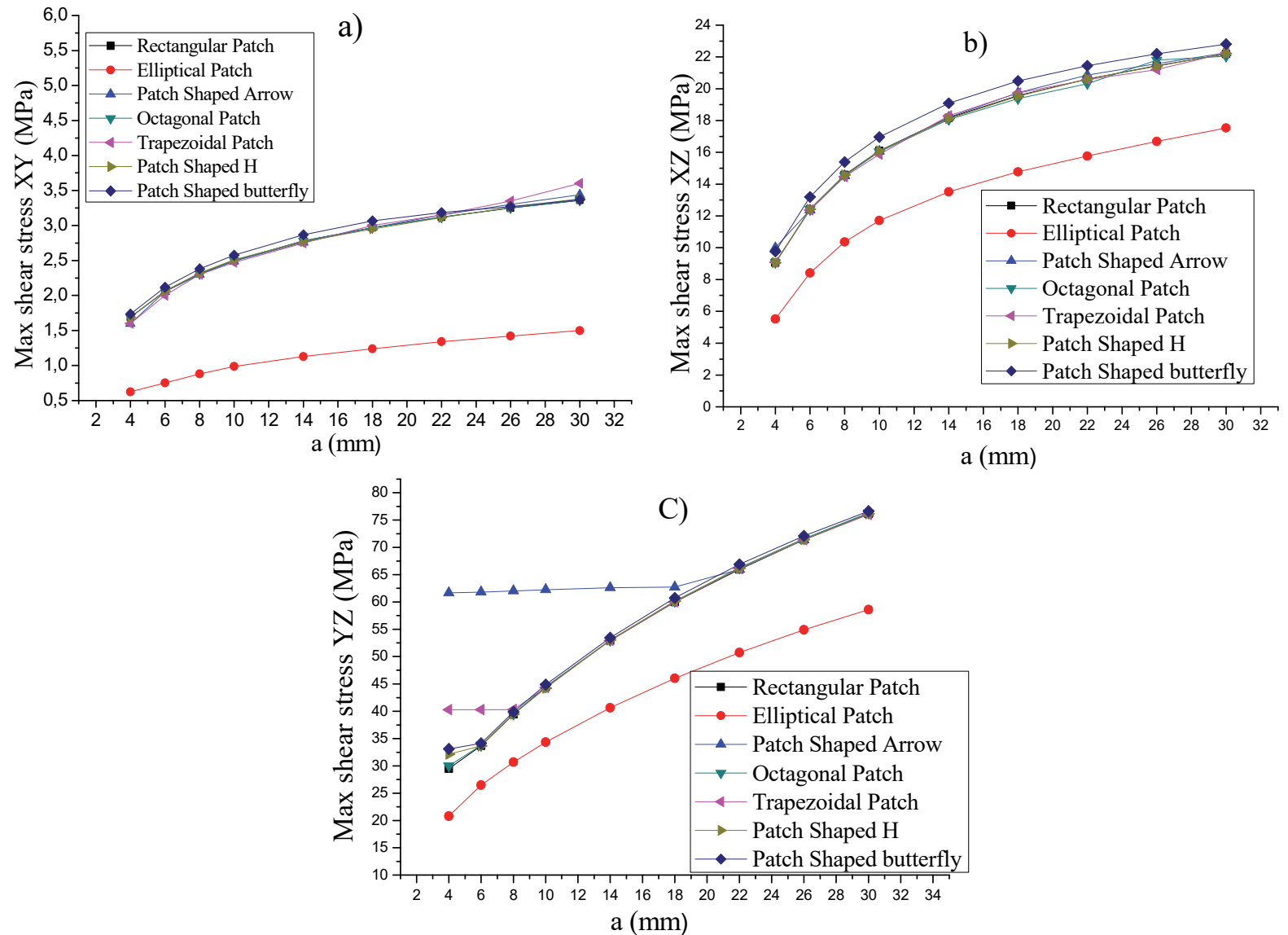

Figure 14: Effect of the patch shape on the maximum shear stresses level in the adhesive layer, applied stress $=150 \mathrm{MPa}$.

\section{Patch with a variation of the surface and conservation of its thickness}

In this part, the patch shapes studied previously with in particular a regression of the surface (fig.8). The effect o0f these shapes on the level and distribution of the shear stresses, is shown in Figs. 15 and 16. These results, show that in terms of minimizing of the shear stresses, relative to the two planes XOY and YOZ ((Fig 15, a and b), the orthogonal and elliptical patch is more efficient. Outside of these two patches, the effect of the patch shapes on the level of these two stresses hardly appears. Our results show that, compared to all the patch shapes analysed, the elliptical and orthogonal patch minimises considerable the shear stresses in the adhesive (Fig.15a, b) and disadvantage the risk of the repair disbonding. The tangential stresses specific to the YOZ plane are relatively high level, due to the crack opening. They can be responsible for the repair degradation (Fig.15c) by initiation and propagation of cohesive or adhesive cracks in the adhesive layer. The level of these stresses is closely related to the patch surfaces. In fact, more this surface is important, 
more the level of this stresses drops (fig.15c). Thus, the repair with a rectangular patch, results the lowest shear stresses in this adhesive layer.
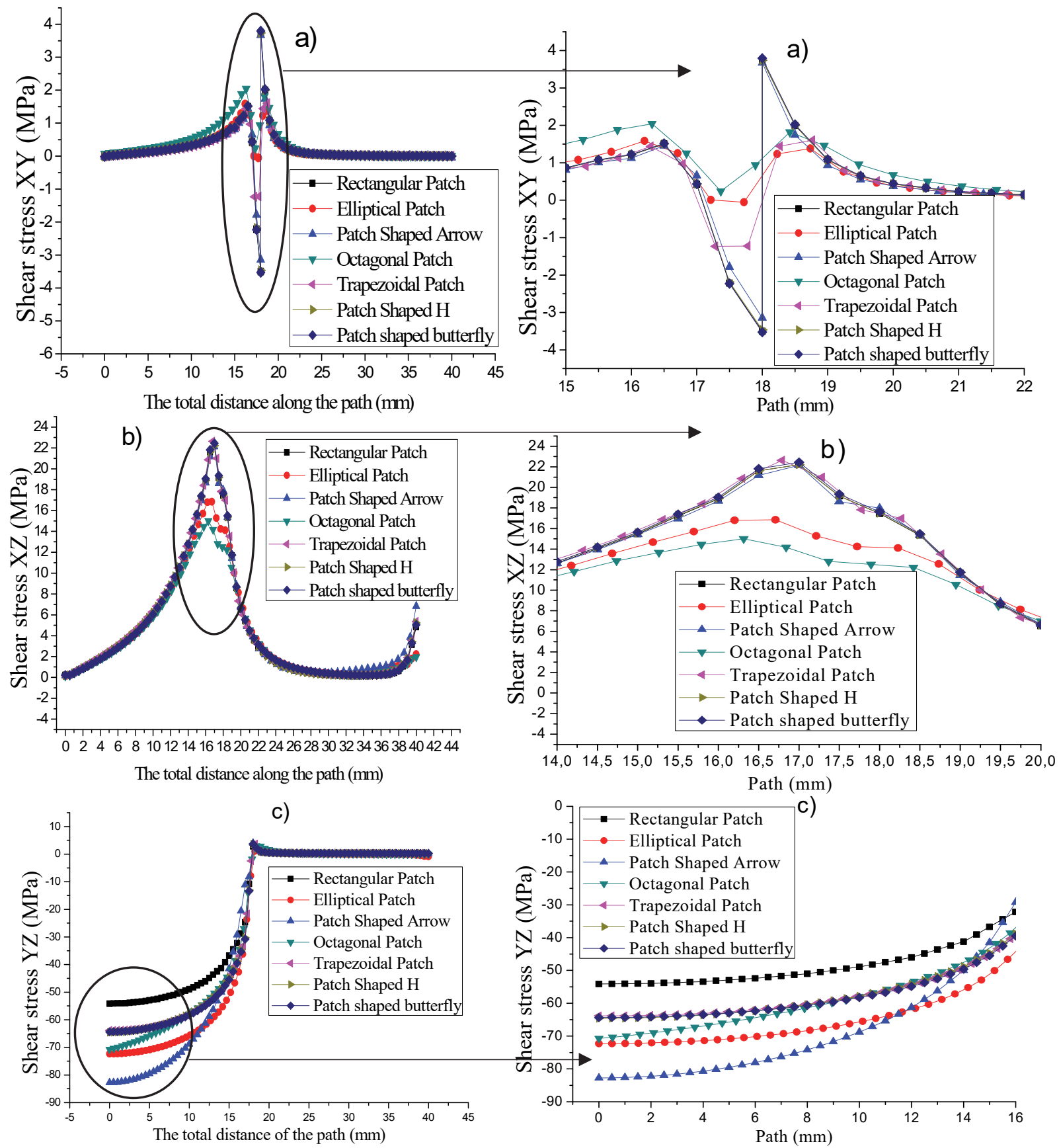

Figure 15: The effect of the patch shape on the shear stresses level in the adhesive layer along the crack propagation path, repaired crack a $=18 \mathrm{~mm}$, Applied stress $=150 \mathrm{MPa}$.

Taking as a criterion the reducing of the maximum stresses induced in the adhesive layer during the commissioning process, the most reliable repair results from an elliptical patch as shown in (Figs. $16 \mathrm{a}, \mathrm{b}$ and c), These figures represent the variation of these stresses generated in the XOY, XOZ and YOZ planes respectively. The stresses on the free edge of the YOZ plane explicitly indicate that these stresses are at the lowest level when the repair is done by an elliptical patch and whatever the sizes of the repaired cracks. This geometry does not present a singular end, or sharp edges can be the seat of stresses concentration, causing the increase of the shear stresses in the adhesive layer. Nevertheless, in our 
simulation conditions, these edges considerably relax the normal tension stresses highly concentrated in the repaired crack heads (Fig 9). Compared to the stresses generated in the XOY plane (Fig. 16a). The maximum tangential stresses in the adhesive layer, relative to the XOZ and YOZ planes (Fig. $16 \mathrm{~b}$ and c), are of a much higher level, and whatever the sizes of the crack and the patch shapes. The intensively stresses generated in the YOZ plane, localised on the free edge of the adhesive, can be sources of initiation and propagation of new cracks in the adhesive, leading to the repair damage by the phenomenon of cracked plate-composite patch disbonding. In fact, the maximum stresses, measured in this adhesive zone, exceed its shear failure threshold. This risk is all the more likely when the crack is of important sizes and whatever the patch shape with which it is repaired (Fig 16c). The important sizes of cracks in our simulations remain theoretical for a better analysis of repair efficiency in terms of reduction of the normal stresses in the crack head. These sizes are mainly responsible for the excessive values of the shear stresses found on this plane of the plate. This last, shows that, whatever the cracks sizes, the failure of the adhesive is most likely when the repair is done by a patch shape having sharp edges of angles acute, straight or obtuse. If such geometries have the advantage to store infinitely intense normal stresses located in the crack heads, they favour the intensification of the shear stresses in the adhesive layer and finally increases the risk of the repair disbonding.
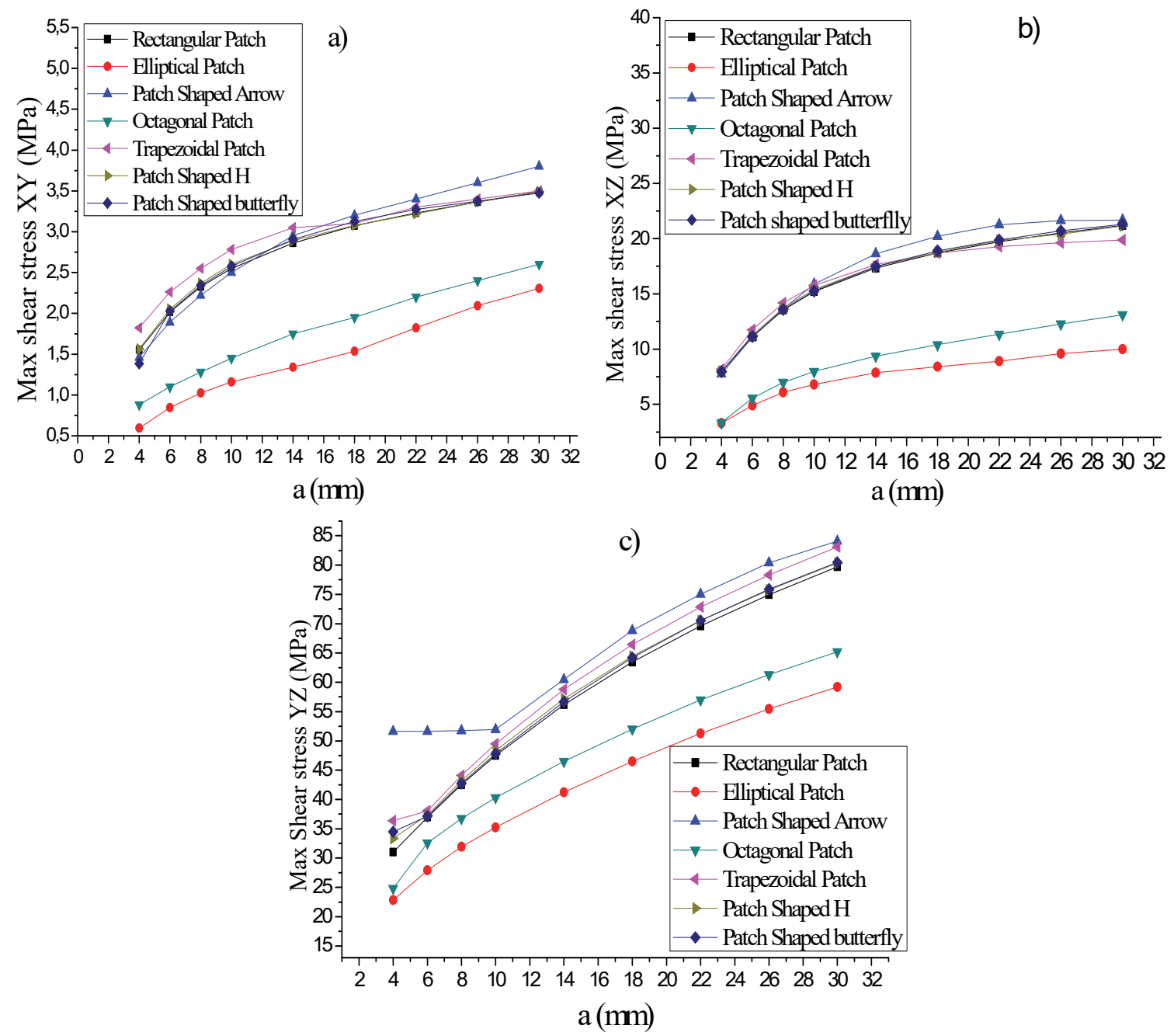

Figure 16: The effect of the patch shape on the maximum shear stresses level in the adhesive layer, applied stress $=150 \mathrm{MPa}$.

\section{Patch with variation of the surface and its thickeness}

The same volume of the patches initially deduced from the rectangular shape has been retained. To complete the previous study, the patches shape differs only in their geometry and their surface. The conservation of the patch volume is done by playing on its thickness (Fig.10). Remember that this thickness is a determining parameter for the repair material stiffness. The conservation of the patches volume with reduced of its surface, require high patch thicknesses which lead to high 
stiffness. For this purpose, and in comparison, with the rectangular patch, a patch shaped arrow with a doubly smaller surface and doubly important stiffness (Fig.10) leads practically to the lower values of the shear stresses relative to the YOZ planes, in the adhesive layer, as shown in (Fig. 17 c). These stresses are due to the crack lips opening (fig. 17c) in mode I.
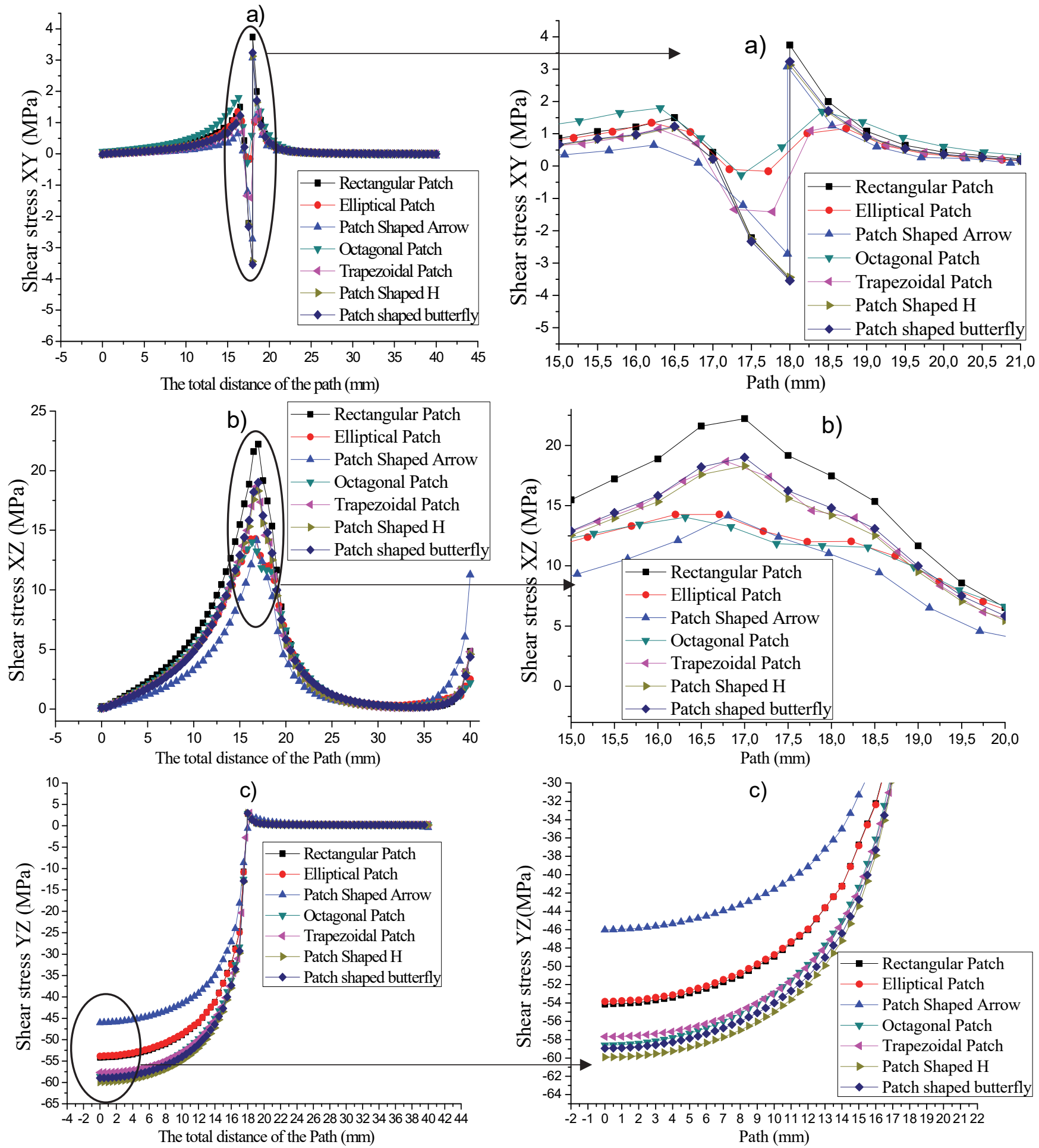

Figure 17: Effect of the patch shapes on the shear stresses level in the adhesive layer along the crack propagation path. repaired crack $\mathrm{a}=18 \mathrm{~mm}$, Applied stress = $150 \mathrm{MPa}$. 
The theoretical sizes of the repaired crack, and the magnitude of the applied stress too high, are responsible for their excessive level. These extreme simulation conditions have been voluntarily used to estimate the repair effectiveness in terms of fracture energy reductions in crack head and tangential stresses in the adhesive layer. It should be noted that the excessive displacement of the crack lips can lead to the disbonding initiation by the adhesive failure. This zone of the plate constitutes a privileged site of the repair damage. These stresses are partly responsible.

The shear stresses generated in the XOY plane are not very intense and whatever the patch shapes used in the repair (Fig.17a). The localised stresses on the XOZ plane of the structure (Fig.17b) are all the weaker when the repair is done by the patches with reduced surfaces, in other words, by using a thicker patch, therefore more stiffness. These stresses do not pose any risk of the adhesive damage.

The maximum shear stresses generated in the XOY, XOZ and YOZ planes of the structure are shown in (Fig. 18), These results show that the most important stresses are located at the free edge (YOZ plane) of the adhesive (Fig.18c). They are all important when the repair uses patches with edge angle obtuse, right or acute. These last, are the seat of the shear stresses concentration. For this purpose, the elliptical shape generates the least intense stresses. These stresses are largely responsible of the patch edges disbonding. So, these results are in good agreement with those obtained by [30,31].
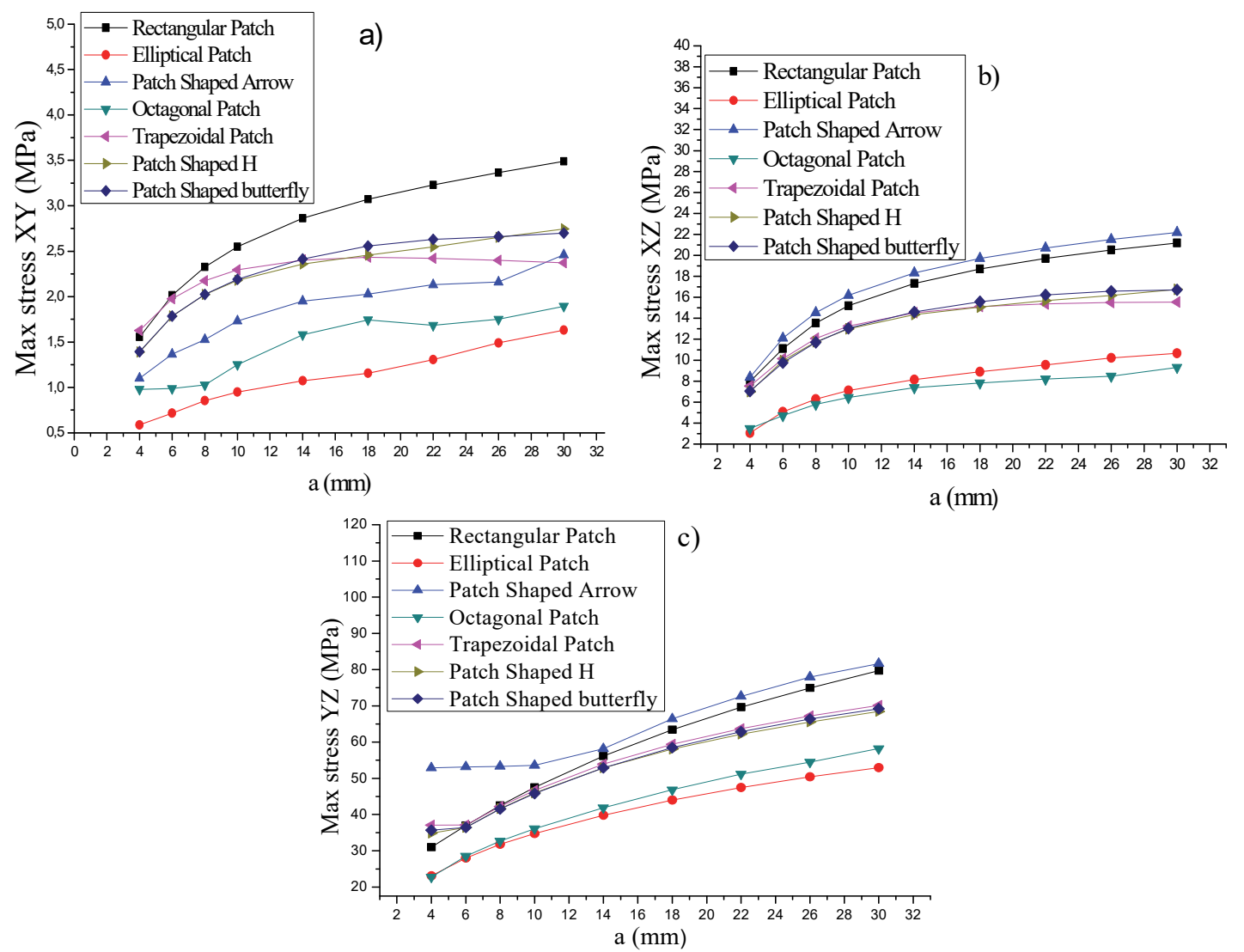

Figure 18: Effect of the patch shapes on the maximum shear stresses level in the adhesive layer, applied stress $=150 \mathrm{MPa}$.

\section{CONCLUSION}

$\mathrm{T}$ his study shows that the performance of the repair, in terms of stress intensity factor reduction, is almost independent of the composite patch shape with the same overlapping surface. Many works $[4,5,13,18$, $19,20,21,22$,] have an interest in the patch shapes effect on the fracture energy level in crack head. The effect of these shapes on the intensity of the shear stresses, relative not only to all the adhesive planes, but also to its free edge, is lacking in these works.

The study proposed here takes into account the patch shapes effect on these two physical parameters reduction (fracture energy and shear stresses). This is the originality of this work. Unlike all the works done until now, this work highlights a site of the adhesive, located in the vicinity very close to the crack lips, where the risk of disbonding is the most privileged. 
This risk is even more likely when the overlapping surface of the crack lips is small using a less stiffness patch. For the same stiffness and for the same overlapping surface, the elliptical shape is the patch geometry, allowing the minimization of these two physical parameters (fracture energy and shear stresses). In this case, the (obtuse, straight, acute) of the patches, located far from the crack head, having no effect on localised tension stresses at the cracking front, these sharp edges are responsible for increasing the shear stresses in the adhesive layer.

The obtaining of different patch shapes from the rectangular classic geometry, is only possible with a reduction of its surface. The seven shapes patch an analysed lead practically the same values of the SIF. This behaviour is due to the modification of the patch morphology and not to the decrease of its surface. Compared to a repair using a rectangular patch, that using a patch shaped arrow, with a doubly reduced overlapping surface, leads to the same level of this fracture energy. This corresponds to a mass gain too important. Nevertheless, this patch shape results the most important shear stresses in the adhesive layer. They have privilege initiation sites of disbonding due to the low overlapping surface of the repaired crack lips. If the sharp edges of this shape have the advantage of storing the highest mechanical energies (normal tension stresses), they are the seat of intensification of shear stresses. The risk of disbonding is very likely when the repair uses this patch shape. This risk is very likely in the adhesive, in the vicinity of the crack lips opening, can be greatly reduced by increasing the stiffness of this patch. Application of a stiffer adhesive to the free edge seems to reduce the maximum shear stresses localised on this portion of this adhesive like suggested by Kaye and al [32] and Wang and al [33].

\section{REFERENCES}

[1] Baker, A.A. (1984). Repair of cracked or defective metallic aircraft components with advanced fiber composites an overview of Australian work. Compos Struct. pp. 2153 -2581. DOI: 10.1016/0263-8223(84)90025-4.

[2] Baker, A.A. and Jones, R. (1988). Bonded Repair of Aircraft Structures. Martinus Nijhoff: Dordrecht. DOI: $\quad 10.1017 /$ S0001924000016560.

[3] Rose, L.R.F. (1982). A cracked plate repaired by bonded reinforcement. Int J Fract 18, pp. $135-144$. DOI: $10.1007 /$ BF00019638.

[4] Bouchiba, S. and Serier, B. (2016). New optimization method of patch shape to improve the effectiveness of cracked plates repair. Structural Engineering and Mchanic. 58(2), pp. 301-326. DOI: 10.12989/sem.2016.58.2.301.

[5] Mhamdia, R., Serier, B., Bachir Bouiadjra, B. and Belhouari, M. (2012). Numerical analysis of the patch shape effects on the performances of bonded composite repair in aircraft structures. Composites: Part B, 43, pp. 391-397. DOI: 10.1016/j.compositesb.2011.08.047.

[6] Chung, K.H. and Yang, W.H. (2003). A study of the fatigue crack growth behavior of thick aluminum panels repaired with composite patch. Composite Structures.60. pp. 1-7. DOI: 10.1016/S0263-8223(02)00095-8.

[7] Chung, K.H., Yang, W.H. and Cho, M.R. (2000). Fracture mechanics Analysis of cracked Plate Repaired by Composite Patch. Key Engineering Material, 43-8, pp. 183-187. DOI: 10.4028/www.scientific.net/KEM.183-187.43.

[8] Jeong, G.H.Y., Won-Ho, Jo. and Myeong, Rae. (2000). Fracture Mechanics Analysis of Cracked Plate Repaired by Patch (I). Transaction of the Korean Society of Material Engineers 24 (8), pp. 2000-2006.

DOI: 10.22634/KSME-A.2000.24.8.2000.

[9] Ramji, M. and Srilakshmi, R. (2012). Design of composite patch reinforcement applied to mixed mode cracked panel using FEA. J Reinf Plast Comp 39(9), pp. 585-95. DOI: 10.1177/0731684412440601.

[10] Ramji, M., Srilakshmi, R. and Bhanu Prakash, M. (2013). Towards optimization of patch shape on the performance of bonded composite repair using FEM, Compos. B. Eng, 45, pp. 710-20. DOI: 10.1016/j.compositesb.2012.07.049.

[11] Kashfuddoja, M. and Ramji, M. (2014). Design of optimum patch shape and size for bonded repair on damaged Carbon fibre reinforced polymer panels. Materials and Design, 54, pp. 174-183. DOI: 10.1016/j.matdes.2013.08.043.

[12] Fekih, S.M., Albedah, A. F., Benyahia Benhouari, M., Bachir Bouadjra, B. and Miloudi, A. (2012). Optimization of the sizes of bonded composite repair in aircraft structures. Matérials \& Design,41, pp. 171-176. DOI: $10.1016 /$ j.matdes.2012.04.025.

[13] Mahadesh, K. and Hakim, S.A. (2000). Optimum design of symmetric composite patch repair to centre cracked metallic sheet.Compos.Struct 49, pp. 285-292. DOI: 10.1016/S0263-8223(00)00005-2.

[14] Ibrahim, N.C.M., Serier, B. and Mechab, B. (2018). Analysis of the crack-crack interaction effect initiated in aeronautical structures and repaired by composite patch, Frattura ed Integrità Strutturale, 46, pp. 140-149. DOI: $10.3221 /$ IGF-ESIS.46.14.

[15] Simulia, Dassault Systems. Abaqus software. Version 6.11. (2011). 
[16] Ouinas, D., Bachir Bouadjra, B., Achour, T. and Benderdouche, N. (2007). The effect of disbands on the stress Intensity Factor of aluminum panels repaired using composite materials. Compos Struct 78, pp. 278-84.

DOI: 10.1016/j.compstruct.2005.10.012.

[17] Brighenti, B. (2007). Patch repair design optimization for fracture and fatigue improvements of cracked plates. International Journal of solids and Structure, 44, pp. 1115-1131. DOI: 10.1016/j.ijsolstr.2006.06.006.

[18] Brighenti, R. (2005). Optimum patch repair shapes for cracked members, Int. J.Mech Mater. 1(4), pp. 365-381. DOI : 10.1007/s10999-005-0525-8.

[19] Ouinas, D., Zenasni, R. and Sahnoun, M. (2011). Effet de la forme géométrique du patch sur la réduction du FIC en mode I. Journées d'Etudes Nationales de Mécanique, Ouargla, Algérie., 07-08 Mars.

[20] Bachir Bouiadjra, B. Fari Bouanani, M. Albedah, A. Benyahia, F. and Es-Saheb, M. (2011). Comparison between rectangular and trapezoidal bonded composite repairs in aircraft structures: A numerical analysis. Materials and Design. 32, pp. 3161-3166. DOI: 10.1016/j.matdes.2011.02.053.

[21] Kaddouri, K., Ouinas, D. and Bachir Bouiadjra, B. (2008). FE analysis of the behavior of octagonal bonded composite repair in aircraft structures. Computational Materials Science, 43, pp. 1109-1111.

DOI: $10.1016 /$ j.commatsci.2008.03.003.

[22] Ouinas, D., Hebbar, A., Bachir Bouiadjra, B., Belhouari, M. and Serier, B. (2009). Numerical analysis of the stress intensity factors for repaired cracks from a notch with bonded composite semicircular patch. Composites Part B Engineering, 40, pp. 804-810. DOI: 10.1016/j.compositesb.2009.06.002.

[23] Apalak, K. M., ApalakGul, Z. and Gunes, R. (2004) Thermal and gemetrically nonlinear stress analyses of an adhesively bonded composite, tee joints with double support. J Thermoplast Compos Mater,17, pp. 10.3-36.

DOI: $10.1177 / 0892705704033337$.

[24] Crombe, A., Richardson, G.P. and Smith, A. (2006). A unified approach for predicting the strength of cracked and non-cracked adhesive joints. Int J Adhes, 49, pp. 211-244. DOI: 10.1080/00218469508014357

[25] Sheppard, A., Kelly, D. and Tong, L. (1998). A damage zone model for the failure analysis of adhesively bonded joints. Int J Adhes, 18, pp. 385-400. DOI: 10.1016/S0143-7496(98)00024-4.

[26] Chang-Su, B., Young-Hwan, L., Jin-Ho, C. and Jin-Hwe, K. (2008), Strength prediction of adhesive joints using the modified damage zone theory. Compos Struct; 86, pp. 96-100. DOI: 10.1016/j.compstruct.2008.03.016.

[27] Nour, C.I., Fari Bouanani, M., Bachir Bouiadjra, B. and Serier, B. (2016). Analysis of the adhesive damage between composite and metallic adherends: Application to the repair of aircraft structures: Advances in Materials Research, 5 (1). pp. 11-20. DOI: 10.12989/amr.2016.5.1.011.

[28] Papanikos, P., Tserpes, K.I. and Pantelakis, S. (2007). Initiation and progression of composite patch debonding in adhesively repaired cracked metallic sheets. Compos.Struct.81, pp. 303-311. DOI : 10.1016/j.compstruct.2006.08.022.

[29] Maglhaes, A.G., De Moura, M.F.S.F. and Gonçaves, JPM. (2005). Evaluation of stress concentration effects in singlelap bonded joints of laminate composite materials. Int J Adhes; 25, pp. 313-9. DOI: 10.1016/j.ijadhadh.2004.10.002.

[30] Da Silva, L. F. M, and Adams, R.D. (2007). Techniques to reduce the peel stresses in adhesive joints with composite. International Journal of adhesive \& Adhesives.27, pp. 227-235. DOI: 10.1016/j.ijadhadh.2006.04.001.

[31] Underhil, P.R. and Du Quesnay, D.L. (2006). The dependence of the fatigue life of adhesive joints on surface preparation. International Journal of Adhesion and Adhesives,26, pp. 62-66. DOI: 10.1016/j.ijadhadh.2005.03.006.

[32] Kaye, R.H. and Heller, M. (2002). Through-thickness shape optimization of bonded repairs and lap-joints International Journal of Adhesion and adhesives,22, pp. 7-21. DOI: 10.1016/S0143-7496(01)00029-X.

[33] Wang, A., Rider, N., Heller, M. and KAYE, R. (2006). Theoretical and experimental research into optimal edge taper of bonded repair patches subject to fatigue loadings. International Journal of adhesion an adhesive,25, pp. 410-426. DOI: $10.1016 /$ j.ijadhadh.2004.11.007. 